\title{
Specificity and Sensitivity of a Human Olfactory Receptor Functionally Expressed in Human Embryonic Kidney 293 Cells and Xenopus Laevis Oocytes
}

\author{
Christian H. Wetzel, Markus Oles, Christiane Wellerdieck, Michael Kuczkowiak, Günter Gisselmann, and \\ Hanns Hatt
}

Lehrstuhl für Zellphysiologie, Ruhr-Universität Bochum, D-44780 Bochum, Germany

\begin{abstract}
Here, we provide the first evidence for functional expression of a human olfactory receptor protein (OR17-40) and show that recombinant olfactory receptors can be functionally expressed in heterologous systems. A mixture of 100 different odorants (Henkel 100) elicited a transient increase in intracellular $\left[\mathrm{Ca}^{2+}\right]$ in human embryonic kidney 293 (HEK293) cells stably or transiently transfected with the plasmid pOR17-40. By subdividing the odorant mixture into progressively smaller groups, we identified a single component that represented the only effective substance: helional. Only the structurally closely related molecule heliotroplyacetone also activated the receptor. Other compounds, including piperonal, safrole, and vanillin, were completely ineffective. Mock-transfected cells and cells transfected with other receptors showed no change in intracellular $\left[\mathrm{Ca}^{2+}\right]$ in
\end{abstract}

The vertebrate olfactory system has enormous discriminatory power (for review, see Lancet, 1986; Reed, 1990; Shepherd, 1994). Humans, for example, are thought to be capable of distinguishing thousands of distinct odor molecules. Subtle alterations in the molecular structure of an odorant can lead to pronounced changes in the perceived odor. The detection of chemically distinct odorants results from the interaction of odor molecules with specific receptor proteins in the ciliary membrane of olfactory receptor neurons. A gene superfamily encoding candidate olfactory receptors was identified (Buck and Axel, 1991). This multigene family contains as many as 1000 genes in rat (Crowe et al., 1996), all belonging to the superfamily of G-protein-coupled receptors with seven putative transmembrane helices. The size of the corresponding gene family in the human genome is unknown, but it has been estimated that there are only 200-500 such genes per genome (Ressler et al., 1994; Rouquier et al., 1998). Human olfactory receptor genes are of particular interest because of the extensive information available about olfactory faculties of Homo sapiens, including basic and applied research on structure-activity relationships and extensive documentation of human olfactory

\footnotetext{
Received May 7, 1999; revised June 3, 1999; accepted June 10, 1999.

This work was supported by Deutsche Forschungsgemeinschaft Grant Ha 1201/ 2-4. We acknowledge the excellent technical assistance of H. Bartel, B. Pohl, and J. Zwoycyk for cell culture and A. Niehaus for preparation of the cRNA. We thank Dr. L. Buck for the I7 plasmid, Dr. Kunzelmann for the CFTR plasmid, and Dr. B. Ache for valuable comments on this manuscript. We are very grateful to Dr. T. Gerke (Henkel KGaA, Düsseldorf, Germany) for the generous gift of the Henkel 100 mixture.

Correspondence should be addressed to Dr. Hanns Hatt, Lehrstuhl für Zellphysiologie, Ruhr-Universität Bochum, Universitätsstraße 150, D-44780 Bochum, Germany.

Copyright (C) 1999 Society for Neuroscience $\quad 0270-6474 / 99 / 197426-08 \$ 05.00 / 0$
}

response to odor stimulation. We were also able to functionally express OR17-40 in Xenopus laevis oocytes. Coexpression of a "reporter" channel allowed measurement of the response of oocytes injected with the cRNA of the human receptor to the odor mixture Henkel 100. The effective substances were the same (helional, heliotropylacetone) as those identified by functionally expressing the receptor in HEK293 cells and were active at the same, lower micromolar concentration. These findings open the possibility of now characterizing the sensitivity and specificity of many, if not all, of the hundreds of different human olfactory receptors.

Key words: human olfactory receptor; functional expression; Xenopus laevis oocytes; HEK293 cell line; structure-activity relationship; calcium imaging; electrophysiology

thresholds for hundreds of odor chemicals (Beets, 1971). The olfactory receptor genes cloned in humans show a high degree of sequence similarity (Selbie et al., 1992; Ben-Arie et al., 1994; Crowe et al., 1996; Rouquier et al., 1998). Members of the gene family have characteristic conserved domains, as well as regions of diversity. Interestingly, multigene families are often found to form gene clusters in the genome (Ben-Arie et al., 1994). Recently, a cluster containing at least 16 olfactory receptor genes was found on human chromosome 17 (Glusman et al., 1996).

The specificity and functional properties of individual receptor proteins in humans are still unknown, however, because human receptors have yet to be functionally expressed. A rat olfactory receptor cDNA clone (OR5) expressed using baculovirus in insect cells showed a surprisingly broad sensitivity to odors of at least five separate chemical classes (Raming et al., 1993). Zhao et al. (1998), using adenovirus to recombinantly express a hybrid mRNA encoding the odorant receptor I7 of the rat, showed that the receptor was highly selective to $n$-octanal. Using a combination of calcium imaging and single-cell reverse transcription-PCR, Malnic et al. (1999) recently found that the olfactory system in mice uses a combinatorial receptor coding scheme to encode odor identities. For more detailed functional characterization, however, a recombinant expression system in heterologous cells has to be established. Recently. Krautwurst et al. (1998) generated an expression library containing a large and diverse repertoire of mouse olfactory receptor sequences and their functional expression in human embryonic kidney 293 (HEK293) cells. Here, we use heterologous systems to characterize the specificity and sensitivity of a human receptor (OR17-40) for the first time. 
A
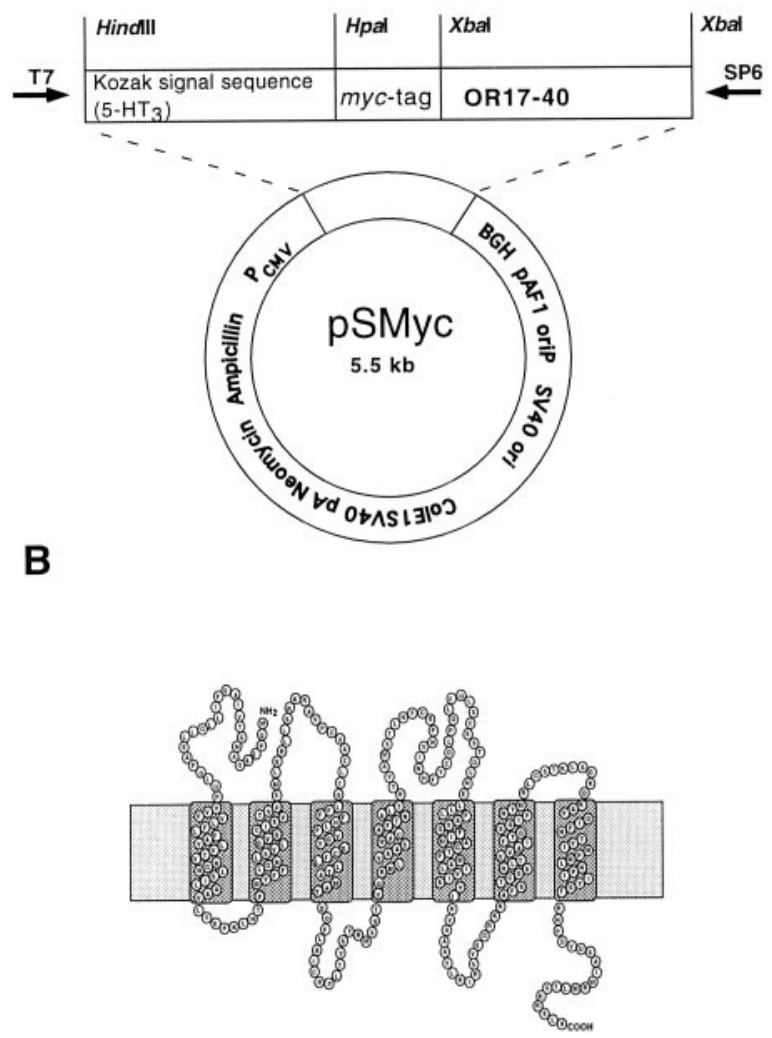

Figure 1. A, Construct of the eucaryotic expression vector $\mathrm{pSMyc}$, which contains a cytomegalovirus promotor and the membrane import sequence of the guinea pig 5-HT 3 receptor, followed by a human myc epitope. The receptor-encoding DNA has been cloned into the $X b a$ I restriction site of this vector to reveal a fusion protein tagged at the extracellular $\mathrm{N}$-terminal site. $B$, In the diagram, the protein encoded by the human OR17-40 gene is presented transversing the plasma membrane seven times, with the $\mathrm{N}$ terminal located extracellularly and the $\mathrm{C}$ terminal intracellularly.

\section{MATERIALS AND METHODS}

Construction of pSMyc. A $130 \mathrm{bp}$ PCR product encoding the membrane import sequence of the 5- $\mathrm{HT}_{3}$ receptor [23 amino acids (aa)] (Lankiewicz et al., 1998) of the guinea pig in frame with the 12 aa peptide MEQKLISEEDLN of the human $c-m y c$ gene (Evan et al., 1985) was obtained via PCR, using $P f u$-DNA buffer (Stratagene, Heidelberg, Germany), $1.5 \mathrm{~mm} \mathrm{MgCl}_{2}, 0.2 \mathrm{~mm}$ of each dNTP, $1 \mathrm{ng} 5-\mathrm{HT}_{3} \mathrm{R}$ cDNA from guinea pig cloned in pRc/CMV (Invitrogen, NV Leek, Netherlands), 0.5 $\mathrm{mM}$ primer $\mathrm{P} 1$ and $\mathrm{P} 2$, and $2.5 \mathrm{U} \mathrm{Pfu}$ polymerase (Stratagene). PCR amplification was performed according to the following schedule: $94^{\circ} \mathrm{C}$ for $1 \mathrm{~min}, 55^{\circ} \mathrm{C}$ for $1 \mathrm{~min}$, and $72^{\circ} \mathrm{C}$ for $1 \mathrm{~min}$ for 30 cycles.

The PCR product was digested with HindIII-XbaI, and the resulting $123 \mathrm{bp}$ fragment was subcloned in $\mathrm{pRc} / \mathrm{CMV}$ (Invitrogen) previously digested with HindIII-XbaI: P1, GCTCTAGATTCAGGTCCTCCTCA CTGATCAGCTTCTGCTCCATGTTAACTTCTCCTTGTGCCAGG GA; P2, CCCAAGCTTGCCACCATGGTGGTGTGGCTCCAGCTG. $X b a \mathrm{I}$ sites are indicated by underlining (Fig. 1).

Construction of pOR17-40. A PCR product containing the coding region of the OR17-40 gene (Crowe et al., 1996; Glusman et al., 1996; gb acc. no.: X80391, U58675) was obtained via PCR, using $P f u$ buffer, 1.5 $\mathrm{mm} \mathrm{MgCl} 2,0.2 \mathrm{~mm}$ of each dNTP, $100 \mathrm{ng}$ of human genomic DNA, 0.5 mM primer P3 and P4, and $2.5 \mathrm{U} \mathrm{Pfu}$ polymerase (Stratagene). PCR amplification was performed according to the following schedule: $94^{\circ} \mathrm{C}$ for $1 \mathrm{~min}, 60^{\circ} \mathrm{C}$ for $1 \mathrm{~min}$, and $72^{\circ} \mathrm{C}$ for $2 \mathrm{~min}$ for 40 cycles. The PCR product was digested with $X b a \mathrm{I}$, and the resulting $963 \mathrm{bp}$ fragment was subcloned in pSMyc (Fig. 1) (Wellerdieck et al., 1997) previously digested with $X b a \mathrm{I}$. The sequence and orientation of the insert was verified by sequencing using the Abi system: P3, GCTCTAGAGCAGCCA GAATCTGGGGCCAATG; P4, GCTCTAGAGAGACCTCCTCAA GCCAGTG. $X b a \mathrm{I}$ sites are indicated by underlining.

Cell culture and transfection of HEK293 cells. HEK293 cells were grown at $37^{\circ} \mathrm{C}$ in MEM (Life Technologies, Gaithersburg, MD) supplemented with $10 \%$ heat-inactivated fetal calf serum, in a humidified $95 \%$ air $-5 \%$ $\mathrm{CO}_{2}$-incubator. Semiconfluent cells were transfected in $35 \mathrm{~mm}$ dishes (Falcon) by using the CaP-precipitation technique as described previously (Zufall et al., 1993) using the plasmid pOR17-40. Efficiency of transfection, typically $<10 \%$, was checked histochemically with the reporter plasmid pCH110 (Pharmacia, Uppsala, Sweden) coding for $\beta$-galactosidase. Measurements were done $48-72 \mathrm{hr}$ after transfection. The stable cell line HEKOR17-40 was obtained by transfection of HEK293 cells with the plasmid pOR17-40 and selection by treatment with G418 (500 mg/l).

A mock-transfected stable cell line (HEK-M) was prepared under the same conditions as described above by transfecting HEK293 cells with the plasmid pSMyc.

Expression of receptor cDNA in Xenopus laevis oocytes. To use pOR17-40 as a template for in vitro transcription, the plasmid was linearized with EcoRV that cleaved 1200 nucleotides downstream the end of the cDNA. For the transcription of human cystic fibrosis transmembrane-conductance regulator (CFTR) RNA, pBSSK/CFTR (Mall et al., 1996) was linearized with KpnI. RNAs were synthesized in the presence of the capping analog $\mathrm{m}^{7} \mathrm{G}\left(5^{\prime}\right) \operatorname{ppp}\left(5^{\prime}\right) \mathrm{G}$ (Pharmacia) using T7- (pOR17-40) or T3-RNA polymerase (pBSSK/CFTR).

The RNA was treated with DNaseI, extracted once with phenol/ chloroform (50:50), ethanol-precipitated, and redissolved in water to give a final concentration of $1 \mu \mathrm{g} / \mu \mathrm{l}$. RNA was analyzed on an agarose gel to ensure that no degradation had occurred. Ovarian lobes were obtained from mature female Xenopus laevis anesthetized by immersion in $0.15 \%$ 3-aminobenzoic acid ethyl ester (methanesulfonate salt; A-5040; Sigma, St. Louis, MO). Ovarian tissue was removed and placed in Barth's solution ( $88 \mathrm{~mm} \mathrm{NaCl}, 1 \mathrm{~mm} \mathrm{KCl}, 0.82 \mathrm{~mm} \mathrm{MgSO}{ }_{4}, 0.33 \mathrm{~mm} \mathrm{Ca}\left(\mathrm{NO}_{3}\right)_{2}$, 0. $41 \mathrm{~mm} \mathrm{CaCl}_{2}, 2.4 \mathrm{~mm} \mathrm{NaHCO} 3,5 \mathrm{~mm}$ Tris-HCl, pH 7.4, $100 \mathrm{U} / \mathrm{ml}$ penicillin, and $50 \mu \mathrm{g} / \mathrm{ml}$ streptomycin) sterilized by filtration $(0.22 \mu \mathrm{M}$ pore filter; Millex-GV; Millipore, Bedford, MA). After treatment of the ovarian tissue with collagenase $\left(2 \mathrm{mg} / \mathrm{ml}\right.$ in $\mathrm{Ca}^{2+}$-free Barth's solution; Type II; C-6885; Sigma) for $2 \mathrm{hr}$ at room temperature, the oocytes were incubated overnight in fresh Barth's solution $\left(20^{\circ} \mathrm{C}\right)$. After $24 \mathrm{hr}$, mature healthy oocytes (stages V-VI) were selected for cytoplasmic injection of cRNA $(\sim 50 \mathrm{nl} /$ oocyte; approximate cRNA concentration of $1 \mu \mathrm{g} / \mu \mathrm{l})$ with a sharp pipette using a pressure injector (PDES 04T; npi, Tamm, Germany). Afterward, injected oocytes were placed again in fresh Barth's solution and incubated at $20^{\circ} \mathrm{C}$. Oocytes were tested for functional expression of CFTR and OR17-40 proteins after 5-7 d.

Electrophysiological recording. The oocytes were voltage clamped with a two-electrode voltage clamp (TURBO TEC-03; npi, Tamm, Germany) to measure their response to odors. The bath contained Xenopus-Ringer's solution (in mM): $115 \mathrm{NaCl}, 2.5 \mathrm{KCl}, 1.8 \mathrm{CaCl}_{2}$, and $10 \mathrm{HEPES}, \mathrm{pH}$ 7.2. The electrodes were filled with $3 \mathrm{M} \mathrm{KCl}$. Odorants were diluted in Xenopus-Ringer's solution to the stated concentration and delivered to the oocytes by means of a multibarrel single-tip superfusion device. The resulting current signals were amplified using pCLAMP software (Axon Instruments, Foster City, CA). Conductance changes were measured as either the slope of the current signal in response to a voltage ramp from -50 to $+50 \mathrm{mV}$ or the amplitude of the current induced by voltage steps $(2 \mathrm{sec})$ from -50 to $+50 \mathrm{mV}$. The magnitude of the response of an oocyte to an odor was calculated as the relative conductance of the oocyte in response to simultaneous application of the odor and $1 \mathrm{~mm}$ 3-isobutyl-1-methylxanthine (IBMX) (test), normalized to the conductance of the oocyte in response to $1 \mathrm{~mm}$ IBMX alone (control). The value of the control conductance used was the mean value of several control measurements taken through the recording period. All test signals that were measurably larger than the mean control signal were accepted as a response so as not to exclude near-threshold responses from the data set.

Calcium imaging. Before an experiment, the culture medium was removed and replaced by the standard experimental solution (in mM: 140 $\mathrm{NaCl}, 5.4 \mathrm{KCl}, 1.8 \mathrm{CaCl}_{2}, 1.0 \mathrm{MgCl}_{2}, 10 \mathrm{HEPES}$, and 5 glucose, $\mathrm{pH} 7.4$ ) containing fura-2 AM $(2-8 \mu \mathrm{M})$ (Molecular Probes Europe BV, Leiden, Netherlands). In some experiments, a $\mathrm{Ca}^{2+}$-free standard solution was used (in mM): $140 \mathrm{NaCl}, 5.4 \mathrm{KCl}, 2$ EGTA, $1.0 \mathrm{MgCl}_{2}, 10 \mathrm{HEPES}$, and 5 glucose, $\mathrm{pH}$ 7.4. The dishes were placed in the incubator for $35 \mathrm{~min}$. Thereafter, the cultures were washed with an excess of fura-2 AM-free 
solution and placed in the incubator for another 60-100 min to allow for cleavage of the ester. The culture dish was placed on the stage of the microscope, and the cells were superfused with $250 \mu \mathrm{l} / \mathrm{min}$ standard solution at $35^{\circ} \mathrm{C}$. Dual-wavelength measurements of fura-2 fluorescence were performed using a setup based on a Zeiss (Köln, Germany) Axiovert 135 microscope. Fura-2 fluorescence measurements were performed by using a multiway wavelength illumination system POLYCHROME II (T.I.L.L Photonics GmbH, Planegg, Germany) for excitation. The microscope was equipped with two long-working distance objectives (Achroplan 63 and Achroplan 40; Zeiss). Spatiotemporal $\mathrm{Ca}^{2+}$-distributions were investigated using a PCO interline chip camera. The wavelength for excitation of the dye was alternated between 340 and $380 \mathrm{~nm}$ and was adapted to the exposure time of the camera $(10-250 \mathrm{msec})$. Acquisition and calculation of the fluorescence images were done using WinNT based-software (T.I.L.L-Vision). All signals were background corrected and calculated. Fluorescence images were displayed in pseudocolors. Images and fluorescence ratios $\left(\mathrm{f}_{340} / \mathrm{f}_{380}\right)$ were stored on the hard disk of a WinNT system. Agonists were applied by means of a solenoid switchoperated superfusion device. The tip diameter of the common outlet tube was $0.5 \mathrm{~mm}$. The half time of exchange between two solutions was $500 \mathrm{msec}$.

Odors. One hundred odorous chemicals (Henkel 100; Henkel, Düsseldorf, Germany) were used, alone or in various combinations. They included odorants from several classes and groups: aromatics, aliphatics, alcohols, aldehydes, esters, ethers, ketones, amines, alkanes, heterocyclics and others. The odorants were stored as a stock solution and diluted just before use with the appropriate physiological solution (1:1000 or $1: 10,000)$. All compounds in the stock solution were at the same concentration $(10 \mathrm{~mm})$.

Henkel 100, helional ( $\alpha$-methyl-3,4-methylendioxy-hydrocinnamaldehyde), heliotropyl acetone, and vanillin were supplied by Henkel. Piperonal, safrole, and the phosphodiesterase inhibitor IBMX were purchased from Fluka/Sigma-Aldrich (Deisenhofen, Germany).

The names of odorants in the Henkel 100 mix are as follows: geranonitrile, acetophenone, eucalyptol, thymol, anethole, menthol, camphor, muscone, citronellol, sweet orange oil, $p$-cymene, eugenol, geraniol, hedione, helional, lyral, D-carvone, L-carvone, citral a, benzyl acetate, sassafras oil, 15-pentadecanolide, methyl salicylate, linalool, phenylethyl alcohol, hexyl cinnamaldehyde $(\alpha)$, amyl cinnamaldehyde $(\alpha)$, iso-bornyl acetate, dihydro myrcene, benzyl salicylate, galaxolide, oil of turpentine, fixolide $\mathrm{np}$, coumarin, styrlyl acetate, piperonal, jonone $(\beta)$, ptbca 25 cis, traseolide, aldehyde $\mathrm{c} 12$, benzyl benzoate, cyclame aldehyde, dmbca, iso-nonyl acetate, benzophenone, bourgeonal, benzyl alcohol, otbca, cinnamyl alcohol, allyl heptanoate, oxyphenylon, cinnamaldehyde, agrunitril, brahmanol, citrathal, dimetol, epitone, iso-nonyl alcohol, phenylethyl acetate, phenirat, aldehyde c08, ethylfruitat, hexyl acetate, neobergamate, aldehyde $\mathrm{c} 12$, anisaldehyde, citrusal, cedryl acetate, ethylvanillin, evernyl, ligustral, dimedone, sandalore, vanillin, aldehyde 1111 , aldehyde 13-13, ambroxan, anthoxan, boisambrene forte, cyclohexyl salicylate, cyclovertal, floramat, herbavert, irotyl, jasmacyclat, melusat, peranat, romilat, sandelice, trivalon, troenan, verdoxan, propidyl, aldehyde $\mathrm{c} 07$, alcohol c08, amylbutyrate, prenylacetate, ethylamylketone, methylhexylketone, acedyl.

\section{RESULTS}

\section{Expression in HEK293 cells: odor-evoked calcium signal}

Recombinant olfactory receptor proteins of fish and Caenorhabditis elegans can be functionally expressed in the plasma membrane of HEK293 cells (Wellerdieck et al., 1997). We initially used this approach to express OR17-40 and analyzed its function by measuring the cell responses to the mixture of chemical stimuli (Henkel 100) by calcium imaging.

In a first set of experiments, we applied the Henkel 100 mixture to HEKOR17-40, the stable cell line transfected with pOR1740. In all cells $(n=138)$, application $(2 \mathrm{sec})$ of Henkel 100 induced a transient $\mathrm{Ca}^{2+}$ signal (Fig. 2B): a relatively rapid increase in intracellular $\left[\mathrm{Ca}^{2+}\right]$, followed by a slower decay $(\sim 5$ sec) to basal level (Fig. 2B, right). After 3-5 min washout, the $\mathrm{Ca}^{2+}$ signal partially recovered. ATP $(1 \mathrm{mM})$ was used as a control for the ability of the cells to increase $\left[\mathrm{Ca}^{2+}\right]$, which presumably would activate the native $\mathrm{P}_{2 \mathrm{Y}}$ receptor expressed by these cells and coupled to the $\mathrm{IP}_{3}$ pathway (Hansen et al., 1993). A strong $\mathrm{Ca}^{2+}$ signal was produced by all cells tested $(n=45)$ (Fig. 2B). In contrast to the stably transfected cells (HEKOR1740 ), only a few transiently transfected cells responded to application of Henkel 100 with a $\mathrm{Ca}^{2+}$ signal (Fig. $2 A$ ). The low number of responding cells correlates with the weak transfection rate $(<5 \%)$ determined by cotransfection of $\beta$-galactosidase-encoding plasmids. Cells transfected with the empty vector never responded to the Henkel 100 mixture, although a strong calcium signal was elicited by application of ATP (Fig. 2C).

\section{Expression in HEK293 cells: odor specificity}

Subdividing the odorant mixture Henkel 100 to smaller groups revealed only one effective substance: helional (Fig. 3). Only one structurally related molecule could be found that activated the receptor: heliotropyl acetone. The time course of the $\mathrm{Ca}^{2+}$ signal elicited by heliotropyl acetone was similar to that shown with Henkel 100 (Fig. 3B). Replacing the $1.8 \mathrm{~mm}$ extracellular $\mathrm{Ca}^{2+}$ with $\mathrm{Ca}^{2+}$-free solution did not alter either the amplitude nor the time course of the Henkel 100 -induced $\left[\mathrm{Ca}^{2+}\right]$ increase (data not shown), suggesting that the increased $\left[\mathrm{Ca}^{2+}\right]$ comes from intracellular stores. Incubation of HEKOR17-40 with the specific protein lipase C (PLC) inhibitor U73122 (Wu et al., 1992) (10 $\mu \mathrm{M})$ for $10 \mathrm{~min}$ significantly reduced (to $\sim 30 \%$ ) the odor-induced increase in $\left[\mathrm{Ca}^{2+}\right]$. The effect was reversible within $15 \mathrm{~min}(n=$ 3) (Fig. 4).

\section{Expression in Xenopus laevis oocytes}

Challenging the expressed odorant receptor protein with the odorant mixture Henkel 100 (1:1000) or the presumptive ligand helional $(500 \mu \mathrm{M})$ failed to produce any detectable current response (data not shown), suggesting the possible absence of a suitable native reporter channel in the oocytes. Therefore, we coexpressed the CFTR as a reporter channel (Uezono et al., 1993; Grygorczyk et al., 1995) with the odorant receptor protein. This allowed the small cAMP signals mediated by the metabotropic odorant receptors to be detected and amplified to much greater extent, for example, than could be achieved by the cAMPactivated channel native to the olfactory neurons themselves (Thürauf et al., 1996). The CFTR protein creates a $\mathrm{Cl}^{-}$channel that increases $\mathrm{Cl}^{-}$conductance after cAMP-induced protein kinase A (PKA)-mediated phosphorylation of the channel protein in the presence of intracellular ATP (Gadsby and Nairn, 1994) (Fig. 5). Enzymatic breakdown of cAMP was prevented by the membrane-permeable phosphodiesterase inhibitor IBMX (1 $\mathrm{mM})$. Odorants presented in the absence of IBMX never produced a measurable increase in membrane conductance (data not shown).

Superfusion of the oocyte with IBMX (1 mM) and the presumptive ligand helional $(500 \mu \mathrm{M})$ increased the membrane conductance 4.5 -fold, from 1.65 to $8.85 \mu \mathrm{S}$, and generated a steadystate inward current of $-800 \mathrm{pA}$ (Fig. 6A). The membrane conductance returned to basal levels after washout of IBMX and helional. One millimolar IBMX alone produced a constant inward current and a 2.8-fold increase in membrane conductance (from 2.2 to $6.05 \mu \mathrm{S}$ ) (Fig. 6A). After washout of IBMX, the membrane conductance decreased to the control level. The response to helional and simultaneously applied IBMX was approximately two times the control response to IBMX alone. Given the likely phosphorylation state of the receptor and channel proteins set by the equilibrium activity of endogenous protein kinases, 

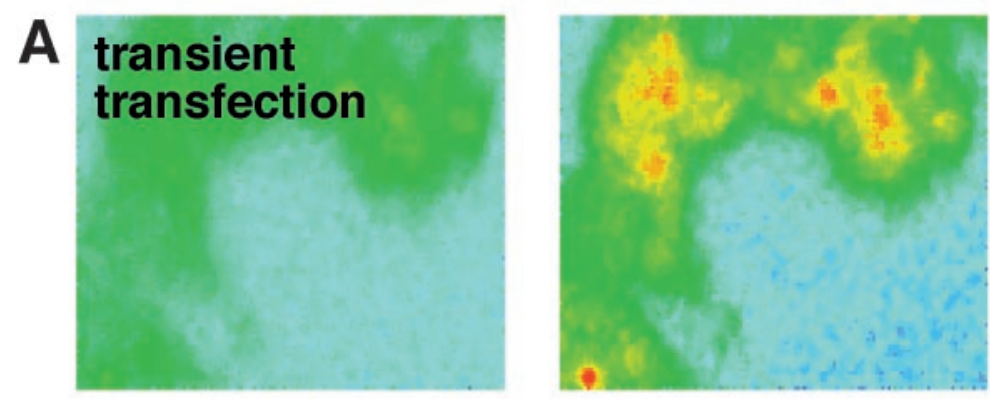

Henkel 100

ATP $1 \mathrm{mM}$
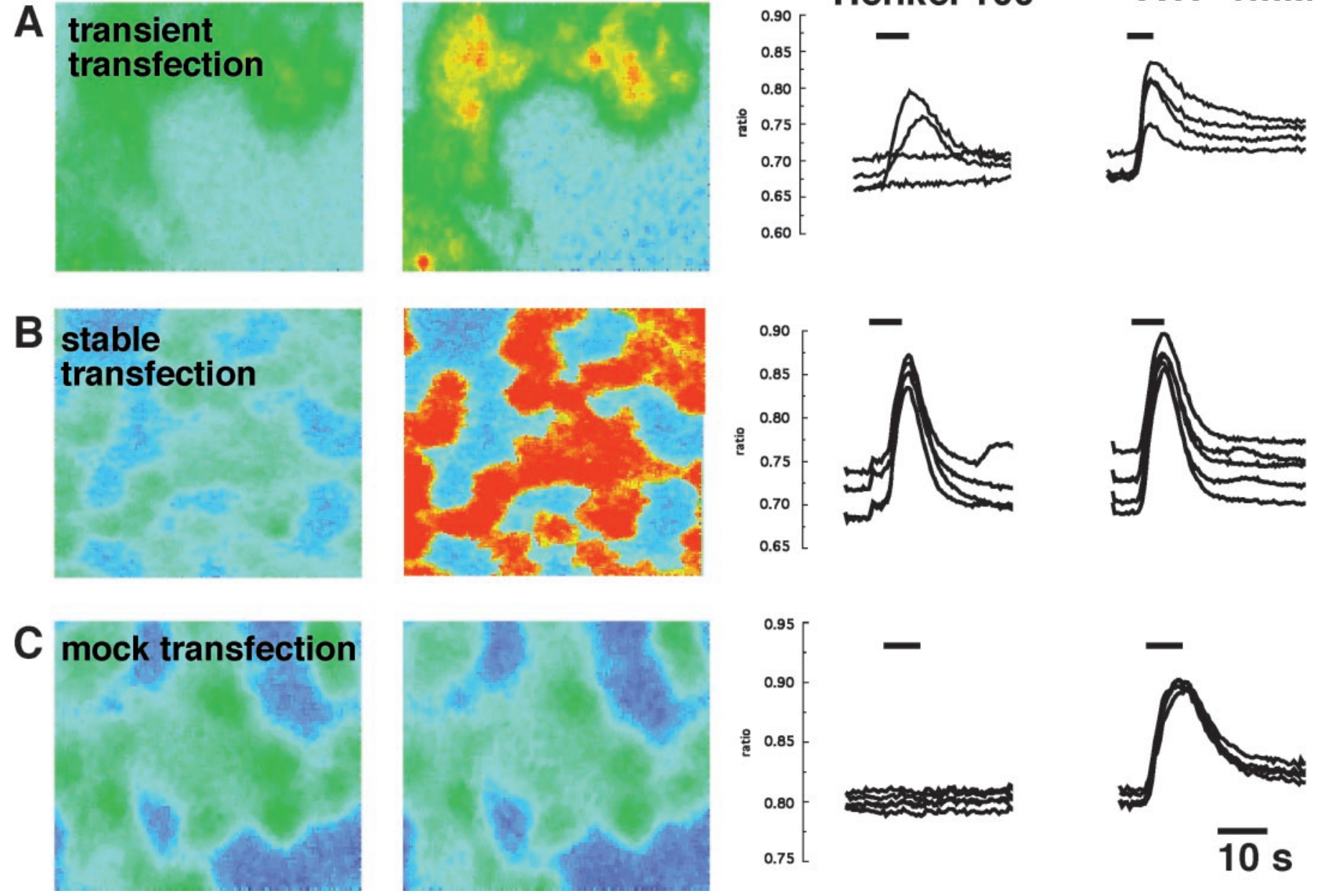

Figure 2. Calcium changes induced by Henkel 100 mixture in various transfected cells; basal $\mathrm{Ca}^{2+}$ distribution in nonstimulated cells (left) is compared with a Henkel 100-stimulated state in which the $\mathrm{Ca}^{2+}$ response is maximal (right). Calcium changes are indicated in pseudocolors. The integrated fluorescence ratio $\left(\mathrm{f}_{340} / \mathrm{f}_{380}\right)$ for different cells measured over time is shown in the two right columns, for Henkel 100 and, as a control, for ATP, which induced $\mathrm{Ca}^{2+}$ signals in all cells tested. The bars indicate the duration of the stimulus application. A, Transiently transfected HEK293 cells; the traces show that only one of the four cells responds to the application of Henkel $100(1: 10,000)$. B. Stably transfected HEK293 cells; all four cells respond to the odorant stimulus. $C$, Mock-transfected cells failed to elicit a $\mathrm{Ca}^{2+}$ response.

phosphatases, and phosphodiesterases, IBMX could be expected to lead to an intracellular increase of cAMP concentration and a subsequent increase of membrane conductance because of the cAMP-induced PKA-mediated phosphorylation and activation of the $\mathrm{CFTR} \mathrm{Cl}^{-}$channel. This result implies that the activation of the odorant receptor and the subsequent (downstream) signal transduction pathway produced an increase of intracellular [cAMP] in addition to the [cAMP] rise caused by inhibition of the degrading phosphodiesterase by IBMX. Hence, we assume that the larger increase in membrane conductance in the presence of the odor compared with that in the control reflects the response of the OR17-40 receptor protein to activation by an odorant ligand.

Figure $6 B$ shows the reproducibility of the response of the injected oocytes expressing the OR17-40 to helional. Repeated application of helional $(500 \mu \mathrm{M})$ and IBMX $(1 \mathrm{mM})$ produced corresponding increases in membrane conductance that were, on average, five times the resting conductance (from 2.1 to $9.9 \mu \mathrm{S}$ ). IBMX alone produced a 2.8 -fold increase in membrane conductance, comparable with that in Figure $6 A$. Henkel 100 also increased the membrane conductance, but a smaller fraction of the
Henkel 100 mix containing 20 different compounds (but not helional) was inactive (data not shown). As a control, we injected oocytes with cRNA of I7 receptor protein of the rat, for which octanal has been demonstrated to be agonistic (Zhao et al., 1998). Indeed, oocytes expressing the $\mathrm{I} 7$ receptor showed a pronounced response to octanal $(500 \mu \mathrm{M})$ but did not respond to helional (500 $\mu \mathrm{M})$ or diacetyl $(500 \mu \mathrm{M})$ (Fig. 7). Conversely, octanal produced no additional membrane conductance in oocytes expressing the OR17-40 (data not shown).

We examined the structure-activity relationship of the OR17-40 by testing the activity of structurally related odorants to helional: piperonal, heliotropyl acetone, safrole, and vanillin. Piperonal, safrole, and vanillin failed to increase the membrane conductance more than IBMX alone $(1.1 \pm 0.1,1.04 \pm 0.1$, and $1.05 \pm 0.1$, respectively; $n=8$ for each odor), i.e., were inactive. Heliotropyl acetone $(10 \mu \mathrm{M})$ increased membrane conductance $1.9 \pm 0.3$ times the control level (IBMX alone) and can therefore be considered as being a functional ligand $(n=8)$. In addition, we investigated the dose-response relationship of the agonistic activity of helional and heliotropyl acetone (Fig. 8). One hundred nanomolar helional increased the membrane conductance $1.6 \pm$ 

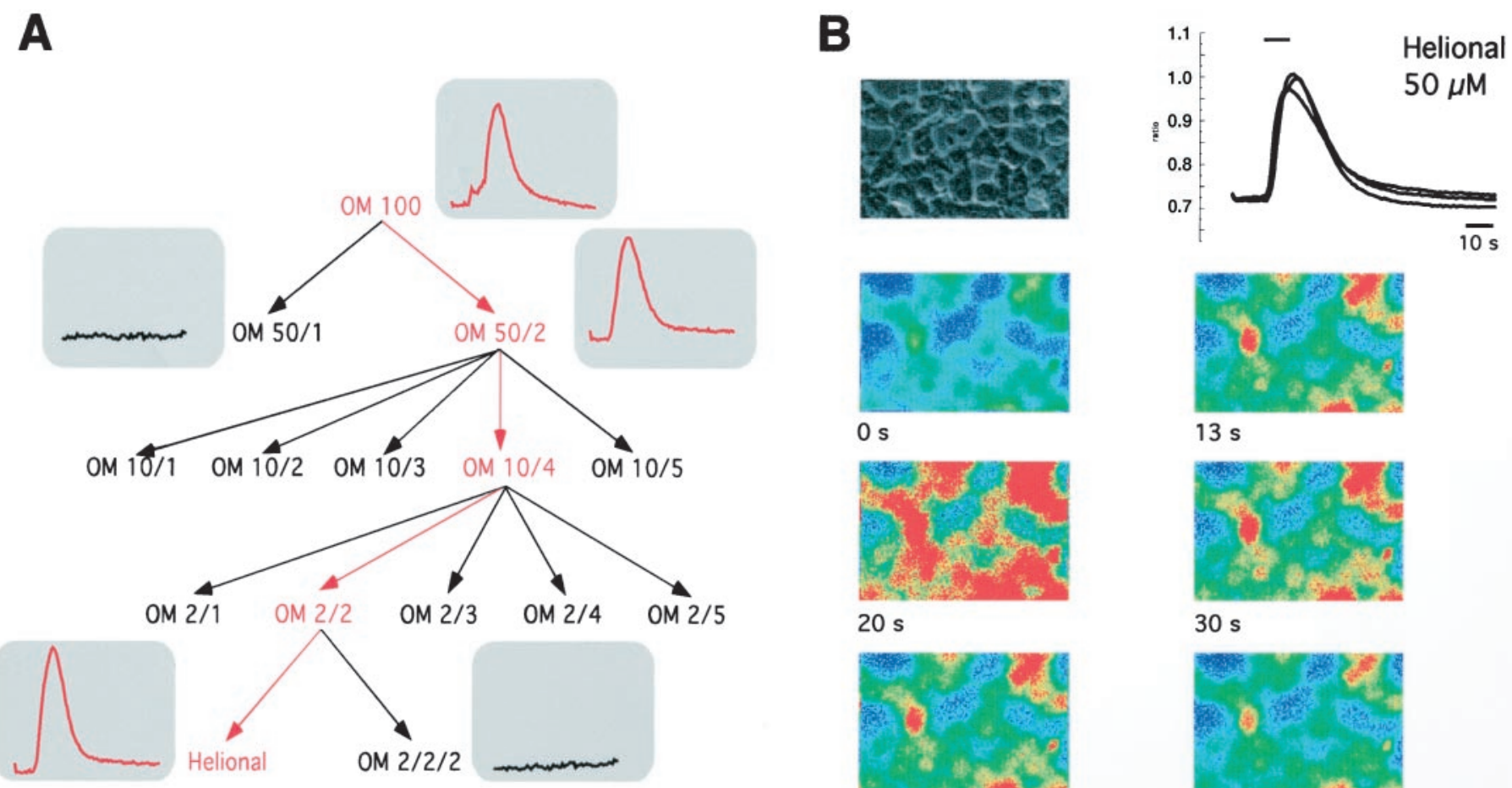

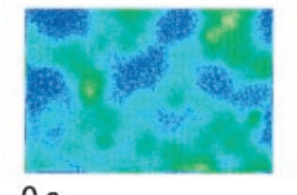

Os

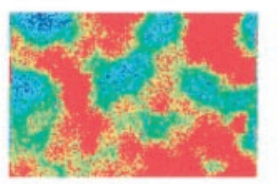

$20 \mathrm{~s}$

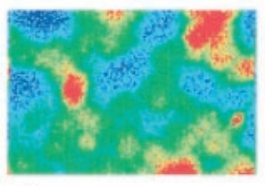

$40 \mathrm{~s}$

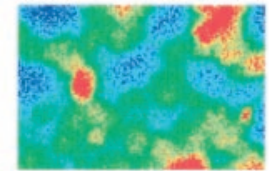

$13 \mathrm{~s}$

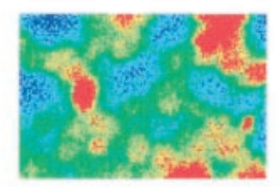

$30 \mathrm{~s}$

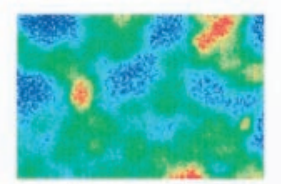

$45 \mathrm{~s}$

Figure 3. A, To identify the effective component(s) in the Henkel 100 solution, the odorant mixture was subdivided into smaller fractions and then tested for activity. The only effective substance was helional; 99 substances were ineffective. $B$, Application of helional (50 $\mu \mathrm{M})$ induced a transient increase in intracellular $\left[\mathrm{Ca}^{2+}\right]$ in a HEK293 cell line, stably transfected with the human OR17-40 odorant receptor. The integrated fluorescence ratio for three different cells measured over time $(40 \mathrm{sec})$ is shown. Changes in intracellular $\left[\mathrm{Ca}^{2+}\right]$ are indicated as changes in color $\left(b l u e\right.$, low $\left[\mathrm{Ca}^{2+}\right]$; red, high $\left.\left[\mathrm{Ca}^{2+}\right]\right)$.

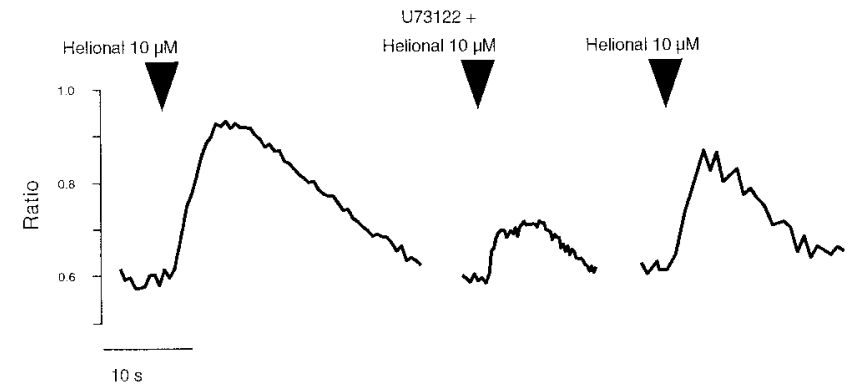

Figure 4. U73122, a specific inhibitor of PLC, reduced the $\mathrm{Ca}^{2+}$ signals induced by helional $(10 \mu \mathrm{M})$. After a control measurement with helional $(10 \mu \mathrm{M})$, the cultures were incubated for 10 min with U73122 $(10 \mu \mathrm{M})$; the resulting significant reduction of the $\mathrm{Ca}^{2+}$ response was reversible after $15 \mathrm{~min}$ washout. The application $(2 \mathrm{sec})$ of helional is indicated by the arrowheads.

0.3 times that of IBMX alone $(n=6)$. One micromolar helional led to a 2.1-fold ( \pm 0.35$)$ and $10 \mu \mathrm{M}$ helional to a 2.7-fold $( \pm 0.6)$ increase in membrane conductance relative to IBMX alone $(n=$ $12)$. Ten and $1 \mu \mathrm{M}$ heliotropyl acetone produced a 1.9-fold $( \pm 0.3)$ and 1.8-fold $( \pm 0.3)$ increase in membrane conductance, respectively $(n=8)$, suggesting there was no distinct dose-dependency of the response in this concentration range.

\section{DISCUSSION}

Our data provide the first evidence for the functional expression and pharmacological characterization of a human olfactory receptor protein in the plasma membrane of heterologous cells. These data are consistent with our previous findings showing that

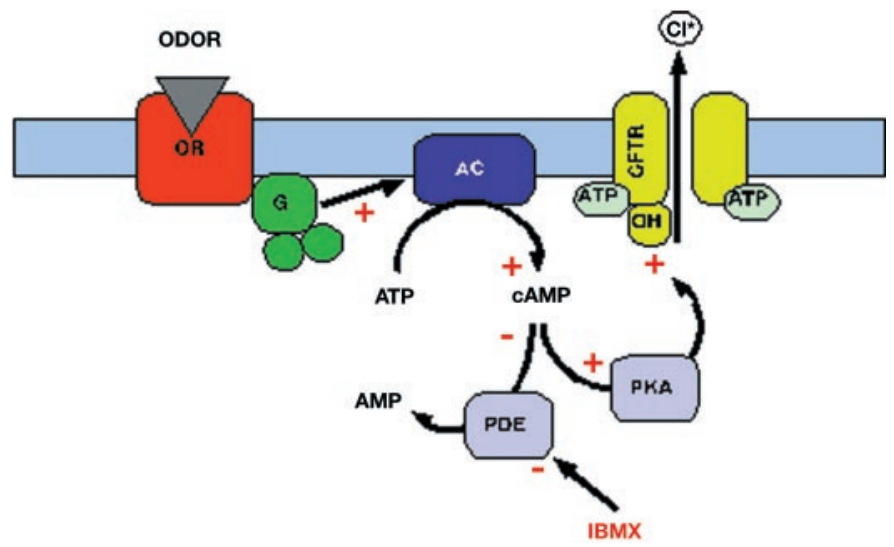

Figure 5. Presumed signal transduction pathway in injected Xenopus laevis oocytes heterologously expressing the odorant receptor OR17-40 and the CFTR. Binding of the agonistic odor to the OR17-40 leads to activation of an endogenous G-protein and stimulation of adenylate cyclase. The resulting increase in intracellular cAMP activates cAMPdependent PKA, which phosphorylates the CFTR protein. The PKAmediated phosphorylation of the CFTR protein in the presence of intracellular ATP leads to opening of the innate $\mathrm{Cl}^{-}$channel and a corresponding increase in membrane conductance. To amplify the signal further, we blocked the enzymatic breakdown of cAMP by application of the membrane-permeable phosphodiesterase inhibitor IBMX (1 mM).

expressed olfactory receptor proteins are inserted into the plasma membrane in the proper orientation and are functional (Wellerdieck et al., 1997). Previously, we were unable to identify a specific ligand for three fish receptors that were expressed functionally in HEK293 cells. Only fish food, an undefined mixture of 
A

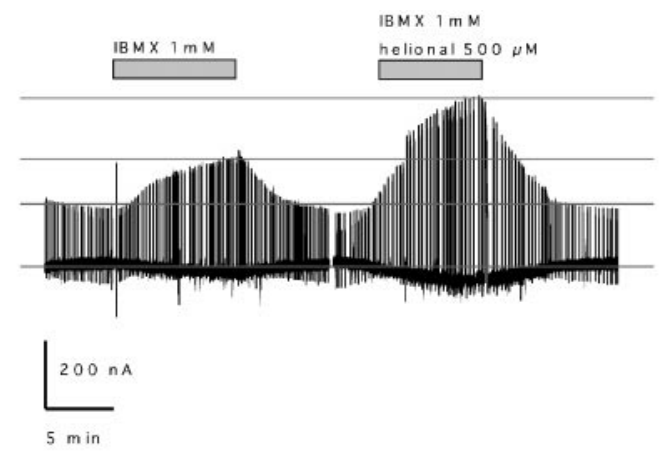

B conductance $[\mu \mathrm{S}]$

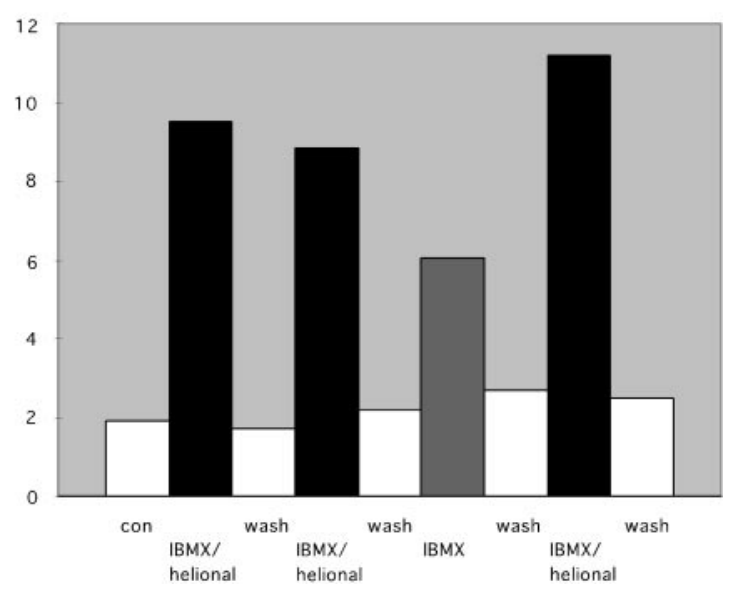

Figure 6. A, Chart recording of a two-electrode voltage-clamp experiment with injected Xenopus laevis oocytes heterologously expressing the odorant receptor OR17-40. The membrane conductance is monitored as the current response to a command voltage step from -50 (holding) to +50 (duration, $2 \mathrm{sec}$ ) $\mathrm{mV}$. Superfusion of the oocyte with IBMX (1 mM) and the presumptive ligand helional $(500 \mu \mathrm{M})$ (indicated by the bar) produced a 4.5 -fold increase in membrane conductance (from 1.65 to 8.85 $\mu \mathrm{S}$ ) and an inward current of $-800 \mathrm{pA}$. After washout, the membrane conductance decreased to the basal level, the same as it was before the coapplication of IBMX and helional (right). Superfusion of the oocyte with IBMX (1 mM) alone produced a 1.8-fold increase in membrane conductance (left). B, Analysis of a representative two-electrode voltageclamp experiment showing the reproducibility of the response of injected oocytes expressing the OR17-40 to helional. Repeated application of helional $(500 \mu \mathrm{M})$ and IBMX $(1 \mathrm{mM})$ produced corresponding increases in membrane conductance to an average of five times the resting conductance (from 2.1 to $9.9 \mu \mathrm{S}$ ). IBMX alone produced a 2.8-fold increase in membrane conductance.

many chemicals, elicited a cell response. We now can identify specific ligands for the expressed human olfactory receptor protein (OR17-40). In addition we established Xenopus laevis oocytes as a new expression system for olfactory receptors. Both expression systems revealed the same structure-activity relationship for OR17-40, indicating that the expression system per se did not selectively influence the specificity of the recombinant receptor.

Identifying the pharmacological characteristics of an olfactory receptor is a critical and important step in understanding olfactory perception. Each olfactory neuron expresses only one receptor and is therefore functionally distinct (Axel, 1995). One difficulty in determining the ligand specificity of odorant receptors is the enormous stimulus repertoire to be tested. We selected a set of 100 odorants that are very frequently used by fragrance companies, including aromatic and short chain aliphatic compounds with various functional groups. Within this set, the OR17-40 receptor exhibits a remarkable ability to discriminate structurally closely related molecules, such as helional and piperonal or helional and safrole. Interestingly, to humans, all three chemicals smell differently as well. The narrow specificity of this odor receptor is similar to that indicated by electrophysiological recordings from single olfactory neurons and mitral cells of the rat olfactory bulb (Sato et al., 1994; Mori and Yoshihara, 1995), and it is also consistent with the adenovirus expression data for the OR-I7 receptor in rat (Zhao et al., 1998). Our results also point in the same direction as the data on functional characterization of chemoreceptors of $C$. elegans. Although the receptor families in C. elegans and humans share essentially no primary sequence homology, both the human receptor and the ODR-10 receptor of C. elegans (responsible for diacetyl detection) display high ligand selectivity (Sengupta et al., 1996; Zhang et al., 1997). These results differ from data obtained by extracellular recording from single rat olfactory neurons (Sicard and Holley, 1984) and membrane preparations from insect SF9 cells infected with a rat olfactory receptor (OR5)-expressing recombinant virus, which showed relatively modest and nonspecific responses to odors of very different chemical classes (Raming et al., 1993). The apparent discrepancy, however, may be related to the expression system, to the method of measuring the signals, or to how the odor stimuli were applied. Clearly, more examples of receptor specificity in the mammalian system will be needed before we know conclusively whether odorant coding is achieved entirely by using highly specific receptors or by combined processing of signals from narrowly tuned and broadly tuned receptors. Recently, Malnic et al. (1999) proposed a combinatorial scheme of action for the olfactory system in mice to encode odor identities. They found that one odorant receptor recognizes multiple odorants and that one odorant is recognized by multiple odorant receptors, but that different odorants are recognized by different combinations of odorant receptors.

The use of olfactory receptor neurons to direct the expression of introduced receptors as in the experiments of Zhao et al. (1998) appears to circumvent the previous difficulties in protein translocation and receptor function. However, there are several disadvantages to this approach. Additional factors expressed by the sensory neurons or the surrounding cells in the tissue could still contribute to ligand binding in this in vivo system, for example odorant-binding proteins that may help to interface odorants with the receptor. This approach also requires signal recognition against relatively high levels of background activity. Interestingly, octanal, the odor studied with this system, is one of the most potent natural stimuli and elicits responses throughout the olfactory epithelium of the rat. Finally, responses to constant stimuli are often not reproducible over time and space, as reflected in electro-olfactogram recordings.

Recombinant expression in heterologous cell lines (HEK293) using calcium imaging avoids some of these problems but, at the same time, introduces inherent disadvantages of itrs own: (1) the calcium signal is not fully reversible and saturates after few odorant applications, (2) detailed pharmacological characterization of receptor specificity requires a stable cell line because of the low transfection rate, and (3) the dose-response relationship is difficult to quantify because of inherent problems quantifying the $\mathrm{Ca}^{2+}$ increase. The Xenopus laevis oocyte system on the other hand avoids these problems: (1) the response of a given receptor population can be measured for many hours, allowing many different mixtures of agonists to be applied during that time, and 


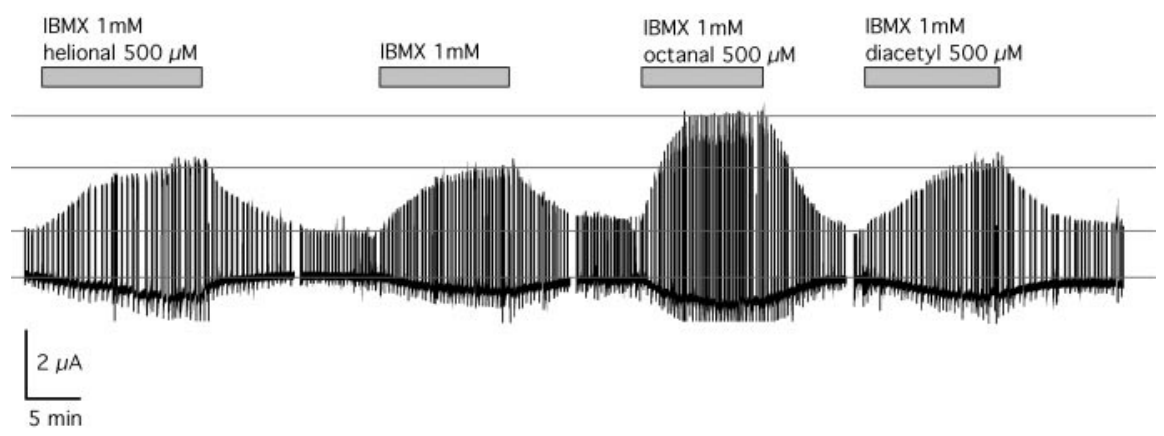

Figure 7. Chart recording of a two-electrode voltage-clamp experiment with injected Xenopus laevis oocytes heterologously expressing the rat odorant receptor I7. The membrane conductance is monitored as the current response to a command voltage step from -50 (holding) to +50 (duration, 2 sec) $\mathrm{mV}$. Superfusion of the oocyte with IBMX $(1 \mathrm{mM})$ and the ligand $n$-octanal $(500 \mu \mathrm{M})$ (indicated by the bar) produced a 2.8 -fold increase in membrane conductance (from 20 to $55 \mu \mathrm{S}$ ) and an inward current of $-800 \mathrm{nA}$. After washout, the membrane conductance decreased to the basal level, the same as it was before the coapplication of IBMX and octanal. Application of IBMX (1 mM), alone or together with helional or diacetyl (500 $\mu \mathrm{M}$ each), produced a 2.1 -fold increase in membrane conductance.

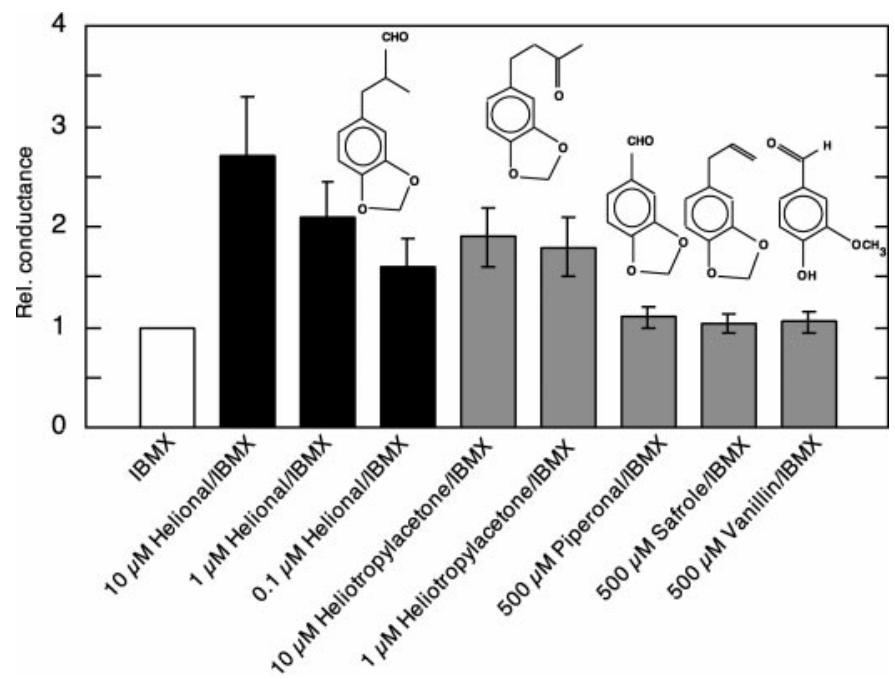

Figure 8. Structure-activity relationship and dose-dependence of various ligands at the OR17-40. The diagram shows the chemical structure of helional and the effect of its action on OR17-40 at three concentrations $(100 \mathrm{nM}, 1 \mu \mathrm{M}$, and $10 \mu \mathrm{M})$, as well as those of heliotropyl acetone (1 and $10 \mu \mathrm{M})$ and of piperonal, safrole, and vanillin (500 $\mu \mathrm{M}$ each). The activity of the tested ligands is shown as relative conductance (mean $\pm \mathrm{SE}$ ), which means that the increase of membrane conductance produced by $1 \mathrm{~mm}$ IBMX is set to 1. Helional and heliotropyl acetone (at the indicated concentrations) activate the OR17-40, whereas piperonal, safrole and, vanillin do not.

(2) the cell response can be quantitatively evaluated. The threshold we report for helional $(\sim 100 \mathrm{~nm})$ is close to the threshold that was found in psychophysical experiments on humans (our unpublished data). The oocyte system allows obtaining dose-response curves and even threshold concentrations that should facilitate understanding the ways odor molecules and receptor molecules interact at the molecular level.

Proteins of the odorant family have a hypervariable region corresponding to the second through fifth transmembrane domains (Lancet and Ben-Arie, 1993; Afshar et al., 1998), the presumed ligand binding site. As for other receptors, it is possible that minor sequence changes, even single residue substitutions, could completely alter odorant binding specificity (Krautwurst et al., 1998). At present, it is not possible to predict whether two olfactory receptor sequences belonging to the same subfamily will actually bind odorants of similar chemical structure. Point mutations and/or the existence of odorant receptors of the same subfamily that differ from each other by only a few residues in this region can now be used to determine precisely the important amino acids involved in the binding of the ligand. It should be possible to construct synthetic ligands (odors) that are much more potent than the natural ones or to create antagonists that can be used to avoid the smell of an unpleasant odor.

\section{REFERENCES}

Afshar M, Hubbard RE, Demaille J (1998) Towards structural models of molecular recognition in olfactory receptors. Biochimie 80:129-135.

Axel R (1995) The molecular logic of smell. Sci Am 273:154-159.

Beets J (1971) Olfactory response and molecular structure. Handbook of sensory physiology 4:257-321.

Ben-Arie N, Lancet D, Taylor C, Khen M, Walker N, Carrozzo R, Patel K, Sheer D, Lehrach H, North MA (1994) Olfactory receptor gene cluster on human chromosome 17: possible duplication of an ancestral receptor repertoire. Hum Mol Genet 3:229-235.

Buck L, Axel R (1991) A novel multigene family may encode odorant receptors: a molecular basis for odor recognition. Cell 65:175-187.

Crowe ML, Perry BN, Connerton IF (1996) Olfactory receptorencoding genes and pseudogenes are expressed in humans. Gene 169:247-249.

Evan GI, Lewis GK, Ramsay G, Bishop M (1985) Isolation of monoclonal antibodies specific for human c-myc proto-oncogene product. Mol Cell Biol 5:3610-3616.

Gadsby DC, Nairn AC (1994) Regulation of CFTR channel gating. Trends Biochem Sci 19:513-518.

Glusman G, Clifton S, Roe B, Lancet D (1996) Sequence analysis in the olfactory receptor gene cluster on human chromosome 17: recombinatorial events affecting receptor diversity. Genomics 37:147-160.

Grygorczyk R, Abramovitz M, Boie Y, Bastien L, Adam M (1995) Detection of adenylate cyclase-coupled receptors in Xenopus oocytes by coexpression with cystic fibrosis transmembrane conductance regulator. Anal Biochem 227:27-31.

Hansen M, Boitano S, Dirksen ER, Sanderson MJ (1993) Intracellular calcium signaling induced by extracellular adenosine $5^{\prime}$-triphosphate and mechanical stimulation in airway epithelial cells. J Cell Sci 106:995-1004.

Krautwurst D, Yau K-W, Reed RR (1998) Identification of ligands for olfactory receptors by functional expression of a receptor library. Cell 95:917-926.

Lancet D (1986) Vertebrate olfactory reception. Ann Rev Neurosci 9:329-355.

Lancet D, Ben-Arie N (1993) Olfactory receptors. Curr Biol 3:668-674.

Lankiewicz S, Lobitz N, Wetzel CHR, Rupprecht R, Gisselmann G, Hatt H (1998) Molecular cloning, functional expression, and pharmacological characterization of 5-hydroxytryptamine ${ }_{3}$ receptor cDNA and its splice variants from guinea pig. Mol Pharmacol 53:202-212.

Mall M, Kunzelmann K, Hipper A, Busch AE, Greger R (1996) cAMP 
stimulation of CFTR-expressing Xenopus oocytes activates a chromanol-inhibitable $\mathrm{K}^{+}$conductance. Pflügers Arch 432:516-522.

Malnic B, Hirono J, Sato T, Buck LB (1999) Combinatorial receptor codes for odors. Cell 96:713-723.

Mori K, Yoshihara Y (1995) Molecular recognition and olfactory processing in the mammalian olfactory system. Prog Neurobiol [Erratum (1995) 46:462] 45:585-619.

Raming K, Krieger J, Strotmann J, Boekhoff I, Kubick S, Baumstark C (1993) Cloning and expression of odorant receptors. Nature 361:353-356.

Reed RR (1990) How does the nose know? Cell 60:1-2.

Ressler KJ, Sullivan SL, Buck LB (1994) A molecular dissection of spatial patterning in the olfactory system. Curr Opin Neurobiol 4:588-596.

Rouquier S, Taviaux S, Trask BJ, Brand-Arpon V, van denEngh G, Demaille J, Giorgi D (1998) Distribution of olfactory receptor genes in the human genome. Nat Genet [Erratum (1998) 19:102] 18:243-250.

Sato T, Hirono J, Tonoike M, Takebayashi M (1994) Tuning specificities to aliphatic odorants in mouse olfactory receptor neurons and their local distribution. J Neurophysiol 72:2980-2989.

Selbie LA, Townsend-Nicholson A, Iismaa TP, Shine J (1992) Novel G protein-coupled receptors: a gene family of putative human olfactory receptor sequences. Brain Res Mol Brain Res 13:159-163.

Sengupta P, Chou JH, Bargmann CI (1996) odr-10 encodes a seven transmembrane domain olfactory receptor required for responses to the odorant diacetyl. Cell 84:899-909.

Shepherd GM (1994) Discrimination of molecular signals by the olfactory receptor neuron. Neuron 13:771-790.
Sicard G, Holley A (1984) Receptor cell responses to odorants: similarities and differences among odorants. Brain Res 292:283-296.

Thürauf N, Gjuric M, Kobal G, Hatt H (1996) Cyclic nucleotide-gated channels in identified human olfactory receptor neurons. Eur J Neurosci 8:2080-2089.

Uezono Y, Bradley J, Min C, McCarty NA, Quick M, Chavkin C, Zinn K, Lester HA, Davidson N (1993) Receptors that couple to 2 classes of $\mathrm{G}$ proteins increase cAMP and activate CFTR expressed in Xenopus oocytes. Receptors Channels 1:233-241.

Wellerdieck C, Oles M, Pott L, Korsching S, Gisselmann G (1997) Functional expression of odorant receptors of the zebrafish Danio rerio and of the nematode C. elegans in HEK293 cells. Chem Senses 22:467-476.

Wu H, James-Kracke MR, Halenda SP (1992) Direct relationship between intracellular calcium mobilization and phospholipase D activation in prostaglandin E-stimulated human erythroleukemia cells. Biochemistry 31:3370-3377.

Zhang Y, Chou JH, Bradley J, Bargmann CI, Zinn K (1997) The Caenorhabditis elegans seven-transmembrane protein ODR-10 functions as an odorant receptor in mammalian cells. Proc Natl Acad Sci USA 94:12162-12167.

Zhao H, Ivic L, Otaki JM, Hashimoto M, Mikoshiba K (1998) Functional expression of a mammalian odorant receptor. Science 279:237-242.

Zufall F, Hatt H, Firestein S (1993) Rapid application and removal of second messengers to cyclic nucleotide-gated channels from olfactory epithelium. Proceedings of the National Academy of Sciences of the United States of America 90:9335-9339. 